\title{
Successful endoscopic retrieval of dislodged jejunostomy Foley catheter
}

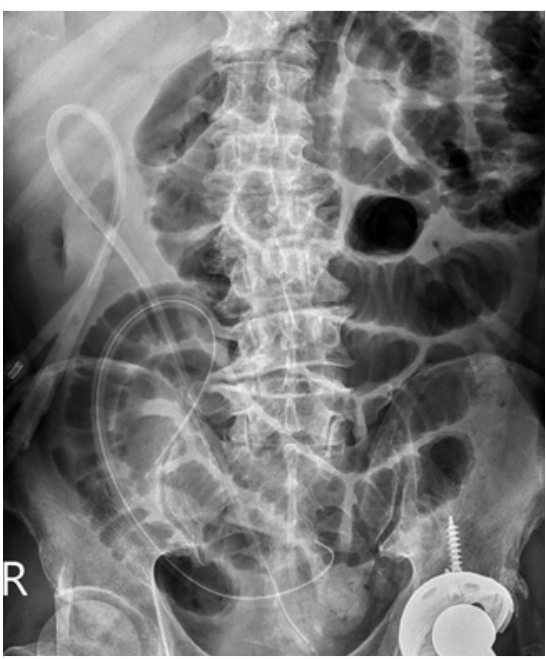

- Fig. 1 Abdominal radiograph revealed the dislodged tube in the right lower abdomen. Proximal small bowel dilatation was observed.

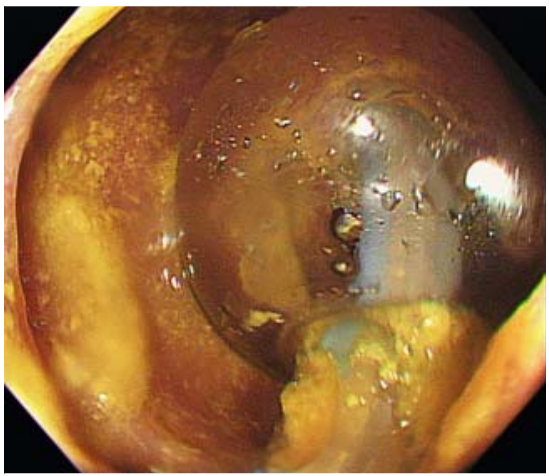

- Fig. 2 Colonoscopy revealed the tip of the feeding tube in the terminal ileum with inflated balloon.

A 56-year-old man who had undergone placement of a feeding jejunostomy secondary to esophageal cancer presented believing that his feeding tube had fallen out but he was unable to locate it in his home. He had not experienced any abdominal pain, tarry stool, intestinal obstruction, or peritonitis. Radiological examination revealed that the missing jejunostomy Foley tube had migrated into the small intestine. Endoscopy failed

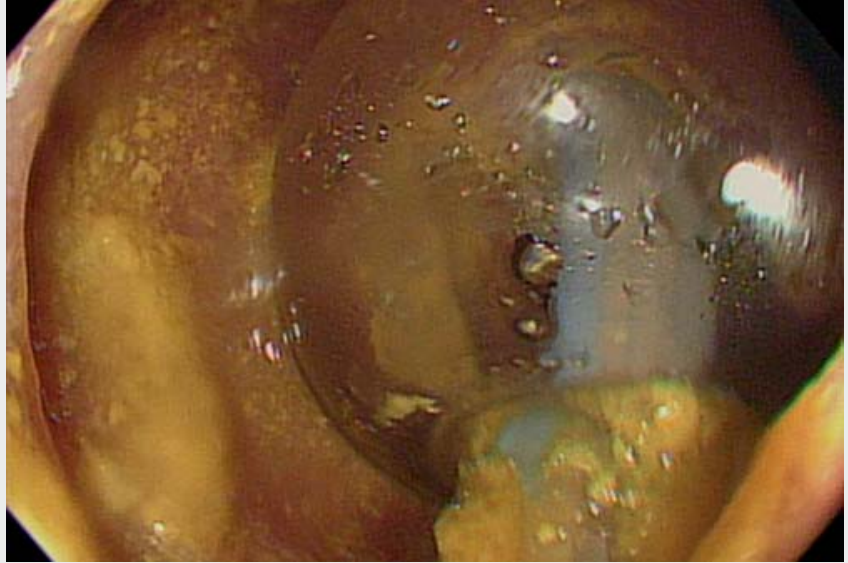

$\square$ Video 1 A jejunostomy Foley tube became dislodged and migrated as far as the terminal ileum, where it became stuck. Attempts using snare or forceps all failed to pull out the impacted catheter. We deflated the balloon after puncturing it with an injection needle and the Foley tube was successfully removed.

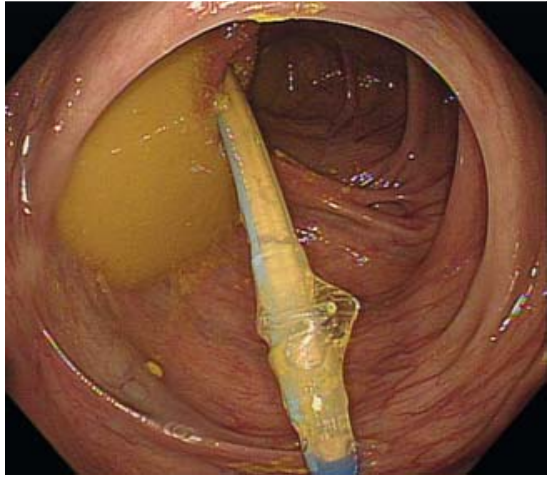

- Fig. 3 Balloon was deflated after injection needle puncture and retracted from the ileum.

to find the migrated tube, which remained stuck over the terminal ileum with proximal small bowel dilatation after 3 days ( $\mathbf{F i g . 1}$ ). We decided to perform endoscopic retrieval and the migrated tube with inflated balloon was found in the terminal ileum ( $\triangleright$ Fig. 2). Attempts using snare or forceps all failed to pull out the impacted catheter due to adhesion resistance. We deflated the balloon after puncturing it with an injec-

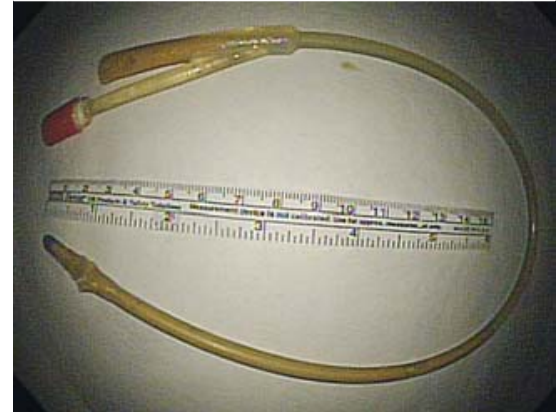

Fig. 4 Colonoscopic view of the retrieved catheter.

tion needle ( $\triangleright$ Video 1 ), and the Foley tube was successfully removed without resistance (> Fig. $\mathbf{3}$, > Fig. 4 ).

A jejunal tube is one of the common methods for providing enteral feeding access for nutritional support [1] when the oral route is restricted or not accessible [2]. Complications of the feeding tube, which include obstruction, intussusception, and migration of the tube, are uncommon [3]. Complete migration is rare and usually requires surgical inter- 
vention if bowel obstruction or peritoneal signs occur [4]. If, as in our patient, the tube is not spontaneously passed out, endoscopic retrieval should be attempted, leaving surgical removal as the last treatment option.

Endoscopy_UCTN_Code_CPL_1AH_2AI

Funding

Changhua Christian Hospital

109-CCH-IRP-008

\section{Competing interests}

The authors declare that they have no conflict of interest.

The authors

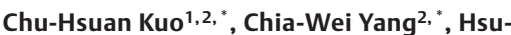
Heng Yen ${ }^{2,3}$ ()

1 Grigore T. Popa University of Medicine and Pharmacy, lasi, Romania

2 Endoscopy Center, Division of Gastroenterology, Changhua Christian Hospital, Changhua Taiwan

3 School of Medicine, Chung Shan Medical University, Taichung, Taiwan
Corresponding author

\section{Hsu-Heng Yen, MD}

Endoscopy Center, Division of

Gastroenterology, Changhua Christian

Hospital, 135, Nanhsiao Street, Changhua 500, Taiwan

Fax: +886-7-7228289

91646@cch.org.tw

\section{References}

[1] Rashid K, Asif M. Complete impulsive migration of feeding jejunostomy tube and jejunal intussusception - sporadic complications of a common procedure. J Coll Physicians Surg Pak 2016; 26: S21-S23

[2] Basil T, Sundaramurthi $S$, Huthalm $S$ et al. Uncommon complication of feeding jejunostomy: a case report. JGH Open 2019; 3 : 444-445

[3] Krishnamurthy G, Pandit N, Singh $\mathrm{H}$ et al. Successful conservative management of spontaneous antegrade migration of feeding jejunostomy. Euroasian J Hepatogastroenterol 2017; 7: 84-86

[4] Ozben V, Karataş A, Atasoy D et al. A rare complication of jejunostomy tube: enteral migration. Turk J Gastroenterol 2011; 22 : 83-85
Bibliography

Endoscopy 2021; 53: E450-E451

DOI 10.1055/a-1322-2062

ISSN 0013-726X

published online 4.2.2021

(C) 2021. Thieme. All rights reserved.

Georg Thieme Verlag KG, Rüdigerstraße 14 ,

70469 Stuttgart, Germany

\section{ENDOSCOPY E-VIDEOS}

https://eref.thieme.de/e-videos

回盾 Endoscopy E-Videos is a free Fin access online section, reporting 回嗮: on interesting cases and new techniques in gastroenterological endoscopy. All papers include a high quality video and all contributions are freely accessible online.

This section has its own submission website at https://mc.manuscriptcentral.com/e-videos

\footnotetext{
* Chu-Hsuan Kuo and Chia-Wei Yang contributed
} equally to the manuscript. 